\title{
Mononuclear Cell Transcriptome Response after Sustained Virgin Olive Oil Consumption in Humans: An Exploratory Nutrigenomics Study
}

\author{
Olha Khymenets, ${ }^{1,2}$ Montserat Fitó, 2,3 María-Isabel Covas,, ${ }^{2,3}$ Magí Farré,,1,4 Maria-Antonia Pujadas,,2 \\ Daniel Muñoz, ${ }^{3}$ Valentini Konstantinidou, ${ }^{2,3}$ and Rafael de la Torre $1,2,5$
}

\begin{abstract}
Virgin olive oil (VOO) is considered to be one of the main components responsible for the health benefits of the Mediterranean diet, particularly against atherosclerosis where peripheral blood mononuclear cells (PBMNCs) play a crucial role in atherosclerosis development and progression. The objective of this article was to identify the PBMNC genes that respond to VOO consumption in order to ascertain the molecular mechanisms underlying the beneficial action of VOO in the prevention of atherosclerosis. Gene expression profiles of PBMNCs from healthy individuals were examined in pooled RNA samples by microarrays after 3 weeks of moderate and regular consumption of $\mathrm{VOO}$, as the main fat source in a diet controlled for antioxidant content. Gene expression was verified by qPCR. The response to VOO consumption was confirmed for individual samples $(n=10)$ by qPCR for 10 upregulated genes (ADAM17, ALDH1A1, BIRC1, ERCC5, LIAS, OGT, PPARBP, TNFSF10, USP48, and XRCC5). Their putative role in the molecular mechanisms involved in atherosclerosis development and progression is discussed, focusing on a possible relation with VOO consumption. Our data support the hypothesis that 3 weeks of nutritional intervention with VOO supplementation, at doses common in the Mediterranean diet, can alter the expression of genes related to atherosclerosis development and progression.
\end{abstract}

\section{Introduction}

A LARGE BODY OF LITERATURE indicates that diet is one of the most important modifiable determinants for the risk of developing cardiovascular diseases (CVDs) (Brunner et al., 2008; Iqbal et al., 2008; Kromhout, 2001; Ordovas et al., 2007; Srinath et al., 2004). The Mediterranean diet, wherein olive oil is the main source of fat, has been shown to be protective against cardiovascular diseases (CVDs) and certain cancers (Trichopoulou et al., 1995, 2003). Virgin olive oil (VOO) is a functional food that contains a high level of monounsaturated fatty acids (MUFA) and a number of minor components. These minor components are classified into two types: the unsaponifiable fraction, and the soluble fraction, which includes the phenolic compounds.

Only recently has VOO been acknowledged as being more than a monounsaturated fat, because its phenolic content provides benefits for plasma lipid concentrations and oxidative damage (Covas et al., 2006; Machowetz et al., 2007). It is believed that the health benefits derived from the consumption of VOO (Estruch et al., 2006; Machowetz et al., 2007) are due to the interaction of its nutrients and minor components with genes, thus influencing their expression (i.e., nutritional transcriptomics). Some of the gene expression-mediated mechanisms underlying the beneficial health effects of particular components of olive oil in humans have been already examined in vitro and in animal models. In one report in cell culture, it was shown that olive oil polyphenols inhibit p38/CREB phosphorylation resulting in downstream reduction in COX-2 expression (Corona et al., 2007). Other reports support the idea that components other than polyphenols from olive oil (e.g., oleanolic acid) may modu-

\footnotetext{
${ }^{1}$ Human Pharmacology and Clinical Neurosciences Research Group, Institut Municipal d’Investigació Mèdica (IMIM-Hospital del Mar), Barcelona, Spain.

${ }^{2}$ CIBER Fisiopatología de la Obesidad y Nutrición (CIBEROBN), Santiago de Compostela, Spain.

${ }^{3}$ Cardiovascular Risk and Nutrition Research Group, IMIM-Hospital del Mar, Barcelona, Spain.

${ }^{4}$ Universitat Autònoma de Barcelona (UAB), Barcelona, Spain.

${ }^{5}$ Universitat Pompeu Fabra (CEXS-UPF), Barcelona, Spain.
} 
late gene expression and upregulation of eNOS protein expression, resulting in an improvement of vasorelaxation in hypertensive rats (Rodriguez-Rodriguez et al., 2007). These findings in cell culture or in animal models are relevant in terms of understanding the interactions of dietary components and gene expression. These experimental models are limited, however, by use of doses/concentrations higher than those encountered in the diet, and difficulties in extrapolating data to humans and clinical practice. A better understanding of the interaction between diet components and human genetic makeup is thus essential to gain mechanistic insights. This may also help to identify individuals who are more likely to display beneficial or toxic responses to dietary interventions (Ordovas et al., 2007).

The peripheral blood mononuclear cells (PBMNCs) play a critical role in the inflammatory pathways that lead to atherosclerosis (Langheinrich and Bohle, 2005; Ross, 1999). The identification of PBMNC genes responding to VOO consumption might offer insight on the biological molecular mechanisms underlying the beneficial action of VOO on human health, particularly in prevention and protection against atherosclerosis. To date, there have been no intervention studies with VOO in humans where the possible interaction between VOO and gene expression has been investigated.

In this exploratory study our objective was to (1) determine whether appreciable changes in PBMNC gene expression after 3 weeks of sustained VOO consumption could be observed and, (2) discuss the putative mechanistic role of the genes whose expression is modulated by VOO consumption. It is anticipated that these findings may serve as a baseline rationale to design future long-term prospective dietary interventions with VOO for prevention of CVDs and to discern the attendant molecular genetic mechanisms.

\section{Materials and Methods}

\section{Description of the dietary intervention: Characteristics of olive oil}

The VOO used in this investigation was of Spanish origin and had been utilized in former studies as well (Estruch et al., 2006). Fatty acid composition, $\alpha$-tocopherol, $\beta$-carotene, and total phenolic content of VOO were determined as described previously (Gimeno et al., 2000; Satue et al., 1994; Singleton and Ross, 1965) (see Supplemental Table 1 for result; see online supplementary material at www.libertonline.com).

\section{Description of the subjects}

Six healthy male (aged 22-28) and four female (aged 20-44) volunteers were recruited. The institutional ethics committee (CEIC-IMAS) approved the protocol and the participants signed an informed consent. All volunteers were healthy on the basis of a physical and medical examination and standard biochemical and haematological tests. Because of the limited number of females the data analysis considered two experimental groups: males $(n=6)$ and a combined group ( $n=10$, including females). Subjects had an average weight of $74.1 \pm 11.7 \mathrm{~kg}$ and $67.2 \pm 13.1 \mathrm{~kg}$, and a body mass index (BMI) of $24.5 \pm 3.5 \mathrm{~kg} / \mathrm{m}^{2}$ and $23.4 \pm 3.1 \mathrm{~kg} / \mathrm{m}^{2}$ for males and for the combined group, respectively. Five subjects were smokers (three males and two females).

\section{Study design, dietary control, VOO administration, and sample collection}

Prior to the dietary intervention, volunteers followed a 1week washout period in which sunflower oil was provided as a source of fat for all purposes. During the first 4 days of the washout period, participants were asked to follow an antioxidant-controlled diet. [Participants were not permitted to eat per day more than: two pieces of fruit, two servings of vegetables or legumes, two cups of tea or coffee, and were instructed to avoid wine, beer, and olive oil.] During the last 3 days of washout and on the intervention day, volunteers followed a strict low-phenolic compound diet. [Phenolic-rich foods (vegetables, legumes, fruit, juice, wine, coffee, tea, caffeine-containing soft drinks, beer, cacao, marmalade, olive oil, and olives) were completely excluded from the participants' diet.] On the first intervention day, at fasting state, 50 $\mathrm{mL}(44 \mathrm{~g})$ of VOO were administered in a single dose with bread (200 g). During the following days, and for 3 consecutive weeks, volunteers consumed $25 \mathrm{~mL}$ (22 g) of VOO per day. Female volunteers were scheduled to start the intervention at the beginning of their follicular phases. Therefore, a period of 4 weeks was chosen for this study as the most practical one with respect to female volunteers' participation and to ensure adherence to the dietary intervention.

Blood and spot urine were collected at 8 a.m. at fasting state: at the beginning of the washout period; prior to VOO consumption on the first intervention day; and at the end of each week during 3 consecutive weeks. Blood samples were used for RNA extraction, biochemical analyses, and in combination with urine samples to ascertain treatment adherence.

Gene expression experiments were performed with samples collected prior to VOO consumption on the first intervention day and at the end of the intervention 3 weeks later. PBMNCs were isolated within $2 \mathrm{~h}$ after blood draw using Vacutainer CPT Tubes (Beckton Dickinson, Franklin Lakes, NJ) according to the manufacturer's instructions. Harvested PBMNCs were preserved in $1 \mathrm{~mL}$ of Ultraspec ${ }^{\circledR}$ solution (Biotecx Laboratories, Houston, TX) and were stored at $-80^{\circ} \mathrm{C}$ prior to RNA extraction.

\section{RNA sample preparation}

A previously validated RNA isolation procedure (Khymenets et al., 2005) was applied for total RNA (RNA) extraction from Ultraspec ${ }^{\circledR}$ preserved PBMNCs. RNA concentration $\left(\mathrm{A}_{260}\right)$ and RNA purity were estimated spectrophotometrically (NanoDrop ${ }^{\circledR}$ ND-1000, NanoDrop Technologies, DE). RNA integrity was assessed by microcapillary gel electrophoresis (Bioanalyzer, NanoChip, Agilent Technologies, Wilmington, DE) and was estimated by the RIN value (RNA integrity number) using Agilent 2100 Expert Software (http://www.chem.agileny.com/scripts). The purity of isolated individual total RNA samples was greater than 1.8 by $\mathrm{A}_{260} / \mathrm{A}_{280}$ and 1.75 by $\mathrm{A}_{260} / \mathrm{A}_{230}$, with integrity values not lower that 8.5 by RIN.

The weight equivalents of individual RNA samples of males corresponding to baseline and to 3-week intervention were combined into two RNA pools, respectively. The pooled RNA samples were concentrated using the RNeasy Mini Elute Cleanup system (Qiagen, Barcelona, Spain) to the concentration $(0.1 \mu \mathrm{g} / \mu \mathrm{L})$ required by the microarray ser- 
vice. The prepared RNA pools were of excellent quality: 1.9 by both $\mathrm{A}_{260} / \mathrm{A}_{280}$ and $\mathrm{A}_{260} / \mathrm{A}_{230}$ ratios and 9.0 by RIN. Pooled and individual RNA samples were stored at $-80^{\circ} \mathrm{C}$ prior to use. All reagents, plastic ware, and supplies used were sterile, nuclease free, and of molecular biology grade.

\section{Microarray experiment}

Genome-wide expression profile analysis of PBMNCs was performed using the Human Genome Survey Microarray V2.0 (Applied Biosystems), which contains 32,878 probes representing 29,098 individual human genes. Three aliquots of pooled total RNA samples, corresponding to baseline and after a 3-week period of VOO consumption, were normalized and analyzed according to the assay protocol standardized for the Human Genome Survey Microarray V2.0 at the National Centre of Cardiovascular Investigation (CNIC, Madrid, Spain). The log2-transformed data were used for the analyses. The identification of genes which were up- and downregulated by VOO ingestion was performed by comparing the gene expression in PBMNCs at baseline and after the 3-week intervention. The cutoffs of -0.5 and 0.5 , corresponding to fold changes of 1.41 (upregulated) and -1.41 (downregulated), at $p<0.05$, were selected on the basis of the variability observed in baseline and intervention samples, both carried out in triplicate (Fig. 1A). The complete sets of microarray data can be accessed from GEO with accession number GSE10590 (http://www.ncbi.nlm.nih.gov/ projects/geo/)

\section{Expression profile representation analysis}

In order to identify the over- and underrepresented gene ontology (GO) categories specific for PBMNC expression profile, as well as in the set of differentially expressed genes, a GO analysis using the PANTHER Classification System (http://www.pantherdb.org/) (Mi et al., 2007; Thomas et al., 2003) was applied. AB Primary Gene ID probes were used in the comparison of the gene lists. First, array data for expressed probes (present and differentially expressed, $n=$ $13,568)$, obtained from the intervention study with reference to baseline, were compared with the gene list of the AB Human Genome Survey Microarray V2.0 $(n=25,909)$ which represents the expression profile of the whole human genome. For each ontology category (biological processes, molecular function, and pathways) PANTHER calculates the number of probes identified in that category in both PBMNCs and reference AB Human Microarray probe lists, and compares these results using the binominal test (Thomas et al., 2006). The PBMNC-specific gene expression profile identified in this manner was used as a reference probe list in comparative GO analysis for differentially expressed genes. In both cases, over- and underrepresentation were defined by $p<0.05$ according to binominal tests (Supplementary Table 2A and 2B). The hierarchy of ontological categories was expressed according to the PANTHER nomenclature.

\section{Gene selection}

Subsequent to the microarray data analysis, a set of genes was chosen for validation by qPCR based on their degree of expression changes ( $M$-value), $p$-values ( $t$-test), B probability (B-statistics) (Fig. 1B) and their role in the development of atherosclerosis and/or cardiovascular pathology, according to the published data (PubMed database (http:// pubmed.gov) of the U.S. National Library of Medicine) (Fig. 1C and Supplemental Table 3).

\section{qPCR experiment}

cDNAs were generated from pooled and individual total RNA samples using the High Capacity cDNA RT Kit (Applied Biosystems, Foster City, CA), according to the manufacturer's instructions. RT was performed in duplicates for each RNA sample and all generated cDNAs were kept at $-20^{\circ} \mathrm{C}$ prior to quantification by PCR. mRNA expression of 23 genes (Fig. 1C and Supplemental Table 3) was measured by real-time PCR using TaqMan ${ }^{\circledR}$ Low Density Micro Fluidic Cards (custom array) on the AB 7900HT ${ }^{\mathrm{TM}}$ instrument and analyzed by Sequence Detection System 2.0 software according to the manufacturer's instructions (Applied Biosystems). Four replicates were run for every RNA sample, two PCR replicates per cDNA replicate. The GAPDH expression was used in normalization. The baseline pooled RNA was used as a calibrator in all relative-relative quantification ( $\mathrm{Li}$ vak and Schmittgen, 2001). The conversion of log2 (ratio) to fold change was performed as follow: Fold Change $=(-1) \times$ $2^{-(\log 2(\text { ratio) })}$ and Fold change $=2^{(\log 2(\text { ratio) })}$ for $\log 2$ (ratio) $<$ 0 and $\geq 0$, respectively.

\section{Markers of VOO consumption}

Plasma and urine concentrations of hydroxytyrosol (HOTYR), tyrosol (TYR), and homovanyl alcohol (HVAlc) were used as markers to control the washout period and VOO consumption using a previously described method (Miró-Casas et al., 2003).

\section{Fasting glucose, lipid profile, inflammation, and oxidative stress markers}

Glucose, total cholesterol, HDL cholesterol, and TG concentrations were determined by enzymatic methods in a Pentra 4000 Autoanalizer (Horiba ABX Diagnostics, Montpellier, France). LDL cholesterol levels were calculated using the Friedewald formula (Friedewald et al., 1972). Circulating oxLDL level in plasma was measured by enzyme-linked immunosorbent assay using the mAb-4E6 antibody (Mercodia AB, Uppsala, Sweden) (Holvoet et al., 2001). Plasma lipid peroxides were assessed by the thiobarbituric acid reactive substance (TBARS) method as previously described (Fitó et al., 2005).

\section{Statistical analysis}

Due to the small sample size (by the Shapiro-Wilk normality test) the changes in all biochemical blood parameters were analyzed using the Wilcoxon signed rank test. Data were expressed as a median (interquartile range) for parameters with a nonnormal distribution in the population and as mean (standard deviation) for normally distributed ones, where changes with $p$-value less than 0.05 were considered significant.

For microarray data analysis, the SpotFire software was used to determine statistically significant changes in the expression of genes. The data on gene expression were presented in $M$-values [log2 (ratio)] expressing a fold change af- 
ter 3 weeks of VOO consumption compared to that at baseline point, and the corresponding $t$ - and $P_{-}, B$-values and $B-$ probability (according to $M$, Student's $t$ - and $B$-statistics, respectively).

The normality of $\log 2$ transformed data obtained by qPCR in the group of males $(n=6)$ and the combined group (males plus females) $(n=10)$ of individuals was assessed using the Shapiro-Wilk test. The data were expressed as mean (SD), and the one-sample Student's $t$-test was used for the evaluation of changes in gene expression. Significance was classified into two levels: a significant change at $p$-value less than 0.05 or 0.01 , and a highly significant one at $p<0.001$.

The data input for correlation studies (Spearman's test) between the microarray and qPCR results for the gene set was the $\log 2$ (ratio) value for pools by microarray ( $M$-value) and qPCR, and a mean of log2 (ratio) values recorded in male individuals. All statistical tests were performed using the SPSS 12.0 software.

\section{Results}

\section{Subject characteristics and blood biomarkers}

Concentrations of all examined biomarkers were within the normal range and no alterations were observed in their levels after 3 weeks of VOO intervention compared to baseline, except for the total level of TG that was slightly lower after the intervention ( $p<0.05$, by Wilcoxon test for the common group, Table 1).

\section{Dietary compliance}

Subjects were adherent to the dietary intervention as evidenced by the plasma and urine concentrations of TYR, HOTYR, and HVAlc after VOO intervention at the morning fasting stage of each weekly visit (Supplemental Fig. 1).

\section{PBMNC gene expression profile}

In order to estimate the specificity of PBMNC gene expression profiles, we compared the list of all expressed Primary Gene probes to a whole set of AB Human Genome Survey Microarray V2.0 Primary probes, using GO analysis by PANTHER Classification System. Thus, 13,568 Primary Gene ID probes corresponding to 15,308 transcription probes were identified as being expressed in PBMNCs. The list of significantly over- and underrepresented PBMNCs categories and the GO analysis results are available as Supplemental Table $2 \mathrm{~A}$ and $2 \mathrm{~B}$.

\section{PBMNC transcriptome response to midterm VOO consumption}

The identification of up- and downregulated genes by comparison of PBMNC gene expression at baseline with that after 3 weeks of $\mathrm{VOO}$ consumption was performed using a combination of cutoffs selected on the basis of $M$ - and Student's $t$-statistics: $\log 2$ (ratio) $(M) \geq 0.5$ (upregulated) and $\leq$ -0.5 (downregulated) (by 1.41- and -1.41 -fold changes, respectively) at $p \leq 0.05$. Using this arrangement, 1,659 Primary Gene probes were found to have their transcription significantly changed (Fig. 1A). Among these, the expression of 1,034 primary probes $(7.6 \%)$ was upregulated and 628 probes $(4.6 \%)$ downregulated. In total, the observed expression changes after 3 weeks of VOO administration were not higher than 1.85 for up and -1.24 for downregulation by log2 (ratio) (3.61 and -2.36 fold change, respectively).

We performed an estimation of over- and underrepresented GO categories in the differentially expressed detected probes, comparing them to the set of PBMNC expressed probes as a reference list. The most significant over- and underrepresented categories whose representation changed after 3 weeks of VOO consumption are listed in Table 2. Amongst these, significantly $(p<0.05)$ overrepresented categories were mainly within upregulated probes, and underrepresented within downregulated ones. No significant changes in the representation of pathways were observed.

\section{Selection of candidate genes}

The previously filtered data were sorted by $B$-probability value of not less than $20 \%(B$-value $>-1.38)$. According to this new cutoff, 317 annotated genes were identified as being potential responders to 3 weeks of VOO consumption (Fig. 1B). These genes were used in the selection of candidate genes, based on published reports concerning their direct or indirect connection with those molecular processes responsible for development and/or progression of atherosclerosis or/and cardiovascular pathologies. Twenty three candidate genes were chosen according to the previously mentioned criteria (Fig. 1C and Supplemental Table 3).

\section{Microarrays and real-time qPCR correspondence}

The selected genes were further tested by real-time quantitative PCR using the pooled samples from microarray experiments and the corresponding original individual samples (from six males). Although a significant correlation of 0.75 and 0.85 ( $r^{2}$ by Spearman, $p<0.001$ for both pooled and individual samples, respectively) was observed between microarrays and qPCR log2 (ratios) (Fig. 2), the changes in expressions were only confirmed by qPCR in both groups of samples for 13 genes (Supplemental Table 4). For the rest of the genes $(n=10)$, their preliminary detected downregulation was ruled out by one or both qPCR experiments (Fig. 3). Finally, 10 genes, whose expression changes were confirmed by both qPCRs, and which were shown to be highly significant $(p<0.001)$ according to the qPCR analysis in a group of individuals (Supplemental Table 4), were considered to be responders to the 3-week VOO consumption (Fig. 3).

To estimate whether the changes induced by 3 weeks of VOO consumption in male PBMNC gene expression could be extrapolated to a combined sample (where females were also included), a separate set of qPCR experiments were performed on individual total RNA samples obtained from female volunteers $(n=4)$ participating in the study. To minimize a possible hormone-dependent variability in PBMNC expression systems for females, sample collection was performed at the beginning of the follicular phases. Individualized changes in the expression of 23 genes of all the individuals according to sex are represented in Fig. 4 . The results grouped for the males and the combined sample are listed in Supplemental Table 5.

All genes previously defined as being significantly upregulated after a 3-week VOO intervention in males showed a significant increase in their expression in the common group (Supplemental Table 5). Moreover, the previously 


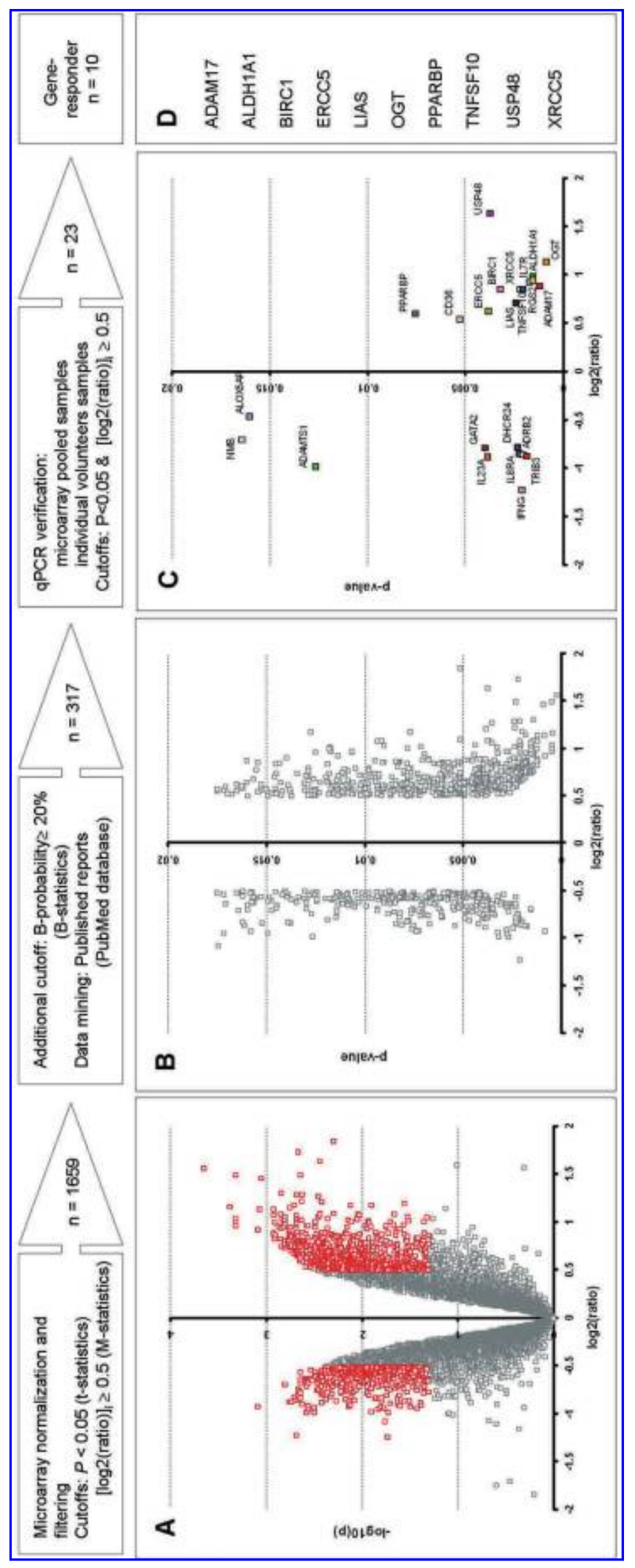

॥

원휴

है

눙

क्ष

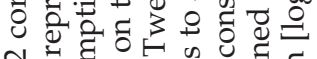
N इ

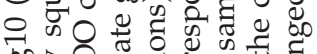

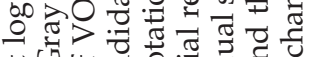
से पे

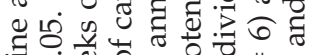
$\exists 0$ ษ

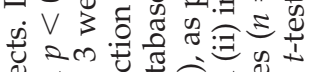

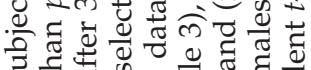

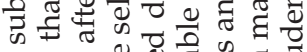

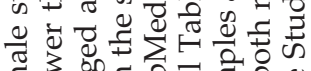

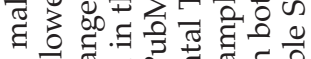

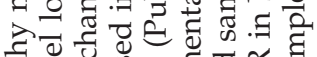

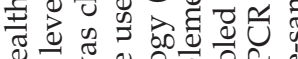

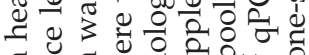

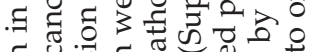
.

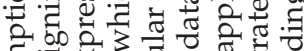
द्वार कर 元 0 记 ठิ นก : $\circ 13$ oे

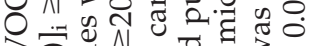

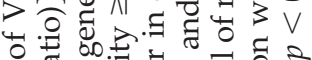

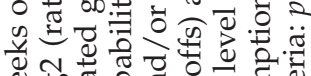
एँ 3 읭.

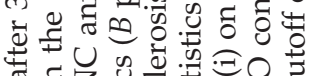

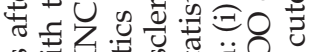

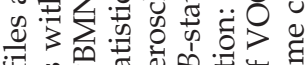

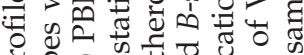
है응. ธ를

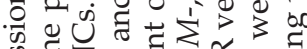

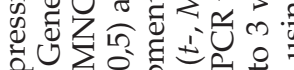

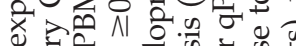
ष द..$\exists$.

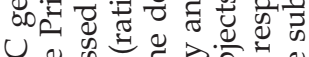
$\checkmark \nsubseteq$ W $\sum_{0}$, 4 政 .

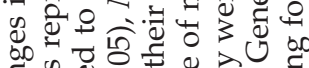

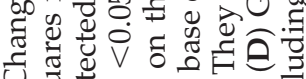

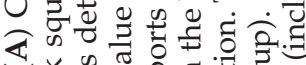
यै

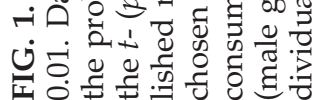


Table 1. Plasma Lipid Profile, Oxidative Stress, Inflammation, and Glycemic Homeostasis Biomarkers ${ }^{\mathrm{a}}$ in Volunteers During Dietary INTERVention ${ }^{\mathrm{b}}$

\begin{tabular}{|c|c|c|c|c|c|}
\hline \multirow[b]{2}{*}{ Biomarkers } & \multirow[b]{2}{*}{ Values } & \multicolumn{2}{|c|}{$\begin{array}{l}\text { Male group } \\
\quad(\mathrm{n}=6)\end{array}$} & \multicolumn{2}{|c|}{$\begin{array}{l}\text { Male and female combined group } \\
\qquad(\mathrm{n}=10)\end{array}$} \\
\hline & & Baseline & 3-week diet & Baseline & 3-week diet \\
\hline \multicolumn{6}{|l|}{ Plasma lipid profile: } \\
\hline total cholesterol & $\mathrm{mg} / \mathrm{dL}$ & $\begin{array}{l}164.00 \\
(17.45)\end{array}$ & $\begin{array}{l}174.67 \\
(30.08)\end{array}$ & $\begin{array}{l}169.10 \\
(27.98)\end{array}$ & $\begin{array}{l}171.80 \\
(27.26)\end{array}$ \\
\hline LDL cholesterol & $\mathrm{mg} / \mathrm{dL}$ & $\begin{array}{l}92.28 \\
(20.48)\end{array}$ & $\begin{array}{l}104.30 \\
(20.03)\end{array}$ & $\begin{array}{l}98.07 \\
(21.37)\end{array}$ & $\begin{array}{l}103.09 \\
(20.46)\end{array}$ \\
\hline HDL cholesterol & $\mathrm{mg} / \mathrm{dL}$ & $\begin{array}{l}57.23 \\
(16.35)\end{array}$ & $\begin{array}{l}57.02 \\
(12.44)\end{array}$ & $\begin{array}{c}56.73 \\
(14.50)\end{array}$ & $\begin{array}{c}56.55 \\
(11.11)\end{array}$ \\
\hline triglycerides (TG) & $\mathrm{mg} / \mathrm{dL}$ & $\begin{array}{c}68.45 \\
(51.85-109.20)\end{array}$ & $\begin{array}{c}62.80 \\
(47.53-86.38)\end{array}$ & $\begin{array}{c}68.45 \\
(47.15-87.87)\end{array}$ & $\begin{array}{c}61.00^{\mathrm{c}} \\
(39.88-69.60)\end{array}$ \\
\hline \multicolumn{6}{|l|}{ Oxidative stress: } \\
\hline oxidized LDL & $\mathrm{U} / \mathrm{L}$ & $\begin{array}{l}66.96 \\
(21.85)\end{array}$ & $\begin{array}{c}80.37 \\
(34.48)\end{array}$ & $\begin{array}{c}63.33 \\
(18.90)\end{array}$ & $\begin{array}{c}71.14 \\
(30.56)\end{array}$ \\
\hline lipid peroxides ${ }^{\mathrm{d}}$ & $\mu \mathrm{mol} / \mathrm{L}$ & $\begin{array}{c}5.37 \\
(2.94-8.46)\end{array}$ & $\begin{array}{c}3.82 \\
(2.92-9.70)\end{array}$ & $\begin{array}{c}3.47 \\
(2.76-7.27)\end{array}$ & $\begin{array}{c}2.87 \\
(2.59-4.72)\end{array}$ \\
\hline \multicolumn{6}{|l|}{ Inflammation: } \\
\hline C-reactive protein & $\mathrm{mg} / \mathrm{L}$ & $\begin{array}{c}0.025 \\
(0.015-0.033)\end{array}$ & $\begin{array}{c}0.020 \\
(0.010-0.065)\end{array}$ & $\begin{array}{c}0.020 \\
(0.015-0.033)\end{array}$ & $\begin{array}{c}0.020 \\
(0.010-0.038)\end{array}$ \\
\hline \multicolumn{6}{|l|}{ Glucose homeostasis: } \\
\hline Serum Glucose & $\mathrm{mg} / \mathrm{dL}$ & $\begin{array}{l}89.67 \\
(5.29)\end{array}$ & $\begin{array}{l}91.65 \\
(6.24)\end{array}$ & $\begin{array}{l}87.01 \\
(5.89)\end{array}$ & $\begin{array}{l}87.5 \\
(7.49)\end{array}$ \\
\hline
\end{tabular}

${ }^{a}$ The data are expressed as median (interquartile range) for parameters with a nonnormal distribution and as a mean (standard deviation) for normally distributed ones. Nonparametrical tests were applied to all biochemical marker comparisons because of the small number of subjects per group.

bAll samples for biochemical measurements were collected in the morning at a fasting stage.

${ }^{c}$ Changed value in comparison to its baseline at significance $p<0.05$ by Wilcoxon test.

${ }^{\mathrm{d}}$ This refers to a concentration of MDA (malondialdehyde), an end product of lipid peroxidation, measured in plasma using the TBARS test.

identified strong responders (ADAM17, ALDH1A1, BIRC1, ERCC5, LIAS, OGT, PPARBP, TNFSF10, USP48, and XRCC5) to 3 weeks of $\mathrm{VOO}$ consumption within the male group ( $p<$ $0.001)$ still displayed highly significant upregulation $(p<$ 0.001) in the combined sample (Fig. 4).

\section{Discussion}

In the present exploratory nutrigenomics study we have compared the PBMNC gene expression profiles after a 1week washout period and following a 3-week consumption of VOO as a principal fat source for healthy human volunteers in a diet low in natural antioxidants. The results contribute toward a foundation to gain novel biological insights into the molecular mechanism underlying the beneficial effects of VOO on the prevention of, and protection against atherosclerosis. Plasma and urine concentrations of olive oil phenolic compounds confirmed adherence by the subjects to the nutritional intervention.

Midterm (3 weeks) regular and moderate consumption of VOO did not significantly influence inflammation and oxidative stress markers, glucose, and lipid profiles (total cholesterol, LDL, and HDL cholesterol concentrations). The lack of significant changes in these parameters is in contrast to previous reports where slight but significant changes in HDL cholesterol and some oxidative markers (e.g., oxLDL) were noted in healthy male individuals after 3 weeks sustained consumption of VOO (Covas et al., 2006). This could be ex- plained by high interindividual variability and a small number of participating subjects in the present study. In addition, we recommend that future studies control for the putative menstrual cycle-dependent changes in gene expression and include a larger number of female subjects (Badeau et al., 2005). Nevertheless, a modest but significant decrease in concentration of plasma TG, particularly in the combined sample, was observed. A change in TG plasma levels might be explained either by (1) the change to MUFA oils as a main fat source (Allman-Farinelli et al., 2005; Kris-Etherton et al., 1999; Trichopoulou et al., 1995), and/or (2) the changes in VLDL composition, which can vary according to the type of dietary MUFA (Ruiz-Gutiérrez et al., 1998) as was reported for the postprandial stage (Abia et al., 2001).

Prior to the differential gene expression analysis, an expression signature of PBMNCs was examined. Evidently, lymphocytes and monocytes have a large number of genes whose expression can distinguish their profile from the whole genome expression set (Supplemental Table 2A and B). A broad spectrum of GO classes (biological process, molecular function, and pathways) was specifically over- and underrepresented in PBMNCs. On the one hand, the underrepresented biological categories were related to the expression of genes involved in certain morphological and physiological cellular specialization not intrinsic for PBMNCs. On the other hand, the overrepresented categories were adequately related to the cellular activities of PBMNCs as immunological cells, combining the gene expression patterns 


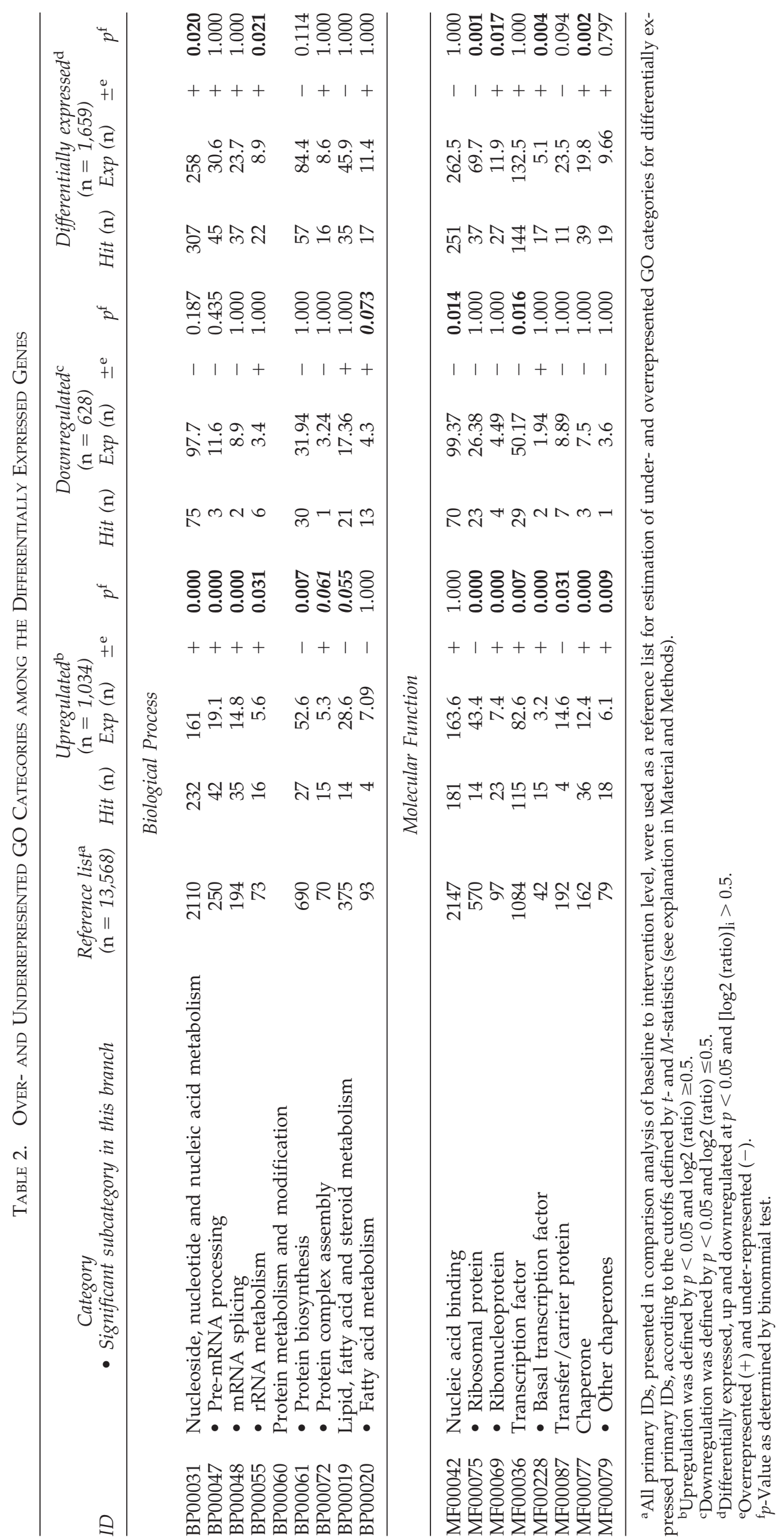




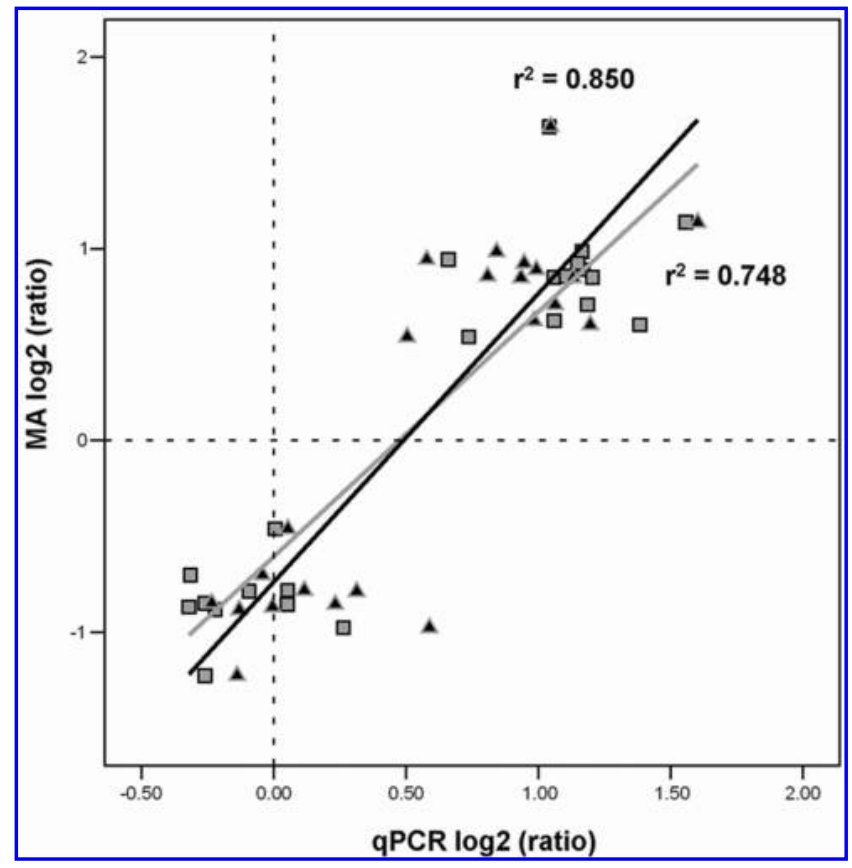

FIG. 2. Comparison microarrays and quantitative real-time PCR reaction. The expression of 23 genes-ADAM17, ADAMTS1, ADRB2, ALDH1A1, ALOX5AP, BIRC1, CD36, DHCR24, ERCC5, GATA2, IFNG, IL23A, IL7R, IL8RA, LIAS, NMB, OGT, PPARBP, RGS2, TNFSF10, TRIB3, USP48, $X R C C 5$ - was studied both individually and in pooled samples by qPCR, normalized to the GAPDH gene, and relatively expressed using as a calibrator baseline pool of RNA. The mean values obtained for $\log 2$ (ratio) from individual analyses (see Supplemental Table 4) are plotted against the microarray values for pooled samples and are expressed as black triangles. The values obtained for pools used in microarrays (see Supplemental Table 4) are plotted against the microarray values for the same pooled samples and are expressed as gray rectangles. Strong concurrence was observed $\left(R^{2}=0.8499, \mathrm{y}=1.277 \mathrm{x}-0.606, p<0.0001\right.$ and $R^{2}=0.7477$, $y=1.504 x-0.7381, p<0.0001$ for mean of $\log 2$ (ratio) individual and pooled samples, respectively).

of different classes of lymphoid and, to some extent, of myeloid (monocytes) tissues (Hashimoto et al., 2003; Palmer et al., 2006). This specific PBMNC gene expression profile was used as a reference profile in the GO analysis of differentially expressed genes.

Changes in the expression of genes were expected to be modest because: (1) the study was performed in healthy volunteers whose gene expression was within the normal variation, and (2) the VOO, itself a component of a normal diet, was supplemented in nutritional doses, and therefore, was not expected to provoke large alterations in gene expression. Nevertheless, the expression of genes is believed to be more sensitive to the nutritional intervention than biochemical parameters. Keeping in mind these constrains, the cutoffs we applied for the selection of differentially expressed genes were of low range. We took into consideration any possible candidate gene whose expression could vary due to the dietetic supplementation we applied, although this alteration could be as slight as a $50 \%$ change.

A GO comparison of all differentially expressed and PBMNCs expressed transcripts has revealed that the representa- tions of a number of the PBMNCs biological processes and molecular functions were considerably altered (Table 2). These rearrangements were most expressed in upregulated and, to a lesser extent, in downregulated genes. Thus, transcriptional factor regulation was misrepresented in both upand downregulated groups, the most outstanding being the overrepresentation of basal transcription factors among the upregulated genes. Ribonucleoproteins, the posttranscriptional regulators (Glisovic et al., 2008), were responsible for both the overrepresentation of pre-mRNA processing and mRNA splicing in upregulated genes. The downregulation of ribosomal protein transcripts, usually highly expressed in lymphoid cells (Murano et al., 2008), indicated some alteration in the translational regulation (Mauro and Edelman, 2002) of these cells. An excessive amount of chaperone transcripts in the upregulated gene group, among the ones most related to nucleophosmin-1 transcripts, indicated that changes had taken place in protein metabolism and modification, and particularly in the regulation of rRNA genes (Murano et al., 2008) and acetylation-mediated chromatin transcription (Swaminathan et al., 2005). Collectively, the GO analysis of the differentially expressed genes indicates that the midterm consumption of VOO could initiate changes in the regulation of transcription and translation activities of PBMNCs. It is of interest that the representation of genes belonging to the lipid, fatty acid, and steroid metabolism has shown some tendency to be altered after the VOO intervention (Table 2). These changes could be related to the adaptive processes that cells developed toward the variation in the fatty acid supplementation caused by the diet (Duplus et al., 2000).

In this study we focused our attention on the beneficial role of olive oil in the protection against CVDs. Our aim was to estimate whether some of the genes involved in atherogenesis could transcriptionally respond to the VOO dietary intervention, and, by extension, be considered as its potential targets of action. A list of genes differentially expressed in PBMNCs in response to the 3-week intervention with VOO was established on the basis of several statistical approaches. An extensive literature search concerning the possible interaction of these genes with, or involvements in atherogenesis was performed. Thus, based on the data reported in Supplemental Table 3, we selected 23 genes of potential interest. The changes in modification of the expression of these genes were analyzed by qPCR in the microarray samples and in the individual RNA samples from the male subjects. We used the pooling sample approach in microarray analysis for two reasons: to optimize the research expenses associated with the study, and because this exploratory nutrigenomics experiment focused on the categorical gene expression response rather than discerning the full range of interindividual biological variation at the whole genome level in response to the VOO. The comparison between microarray and qPCR samples has shown that there was some inconsistency between the results obtained by these two methods. This lack of concordance between methods was only observed in genes with negative expression changes detected by microarrays (Supplemental Table 4, Fig. 3). This observation was not surprising due to the low magnitude of changes and the use of pooled samples, in agreement with the previously published observations (Morey et al., 2006). Nevertheless, in our experience a strategy of pooled samples applied in this study for screening purposes 


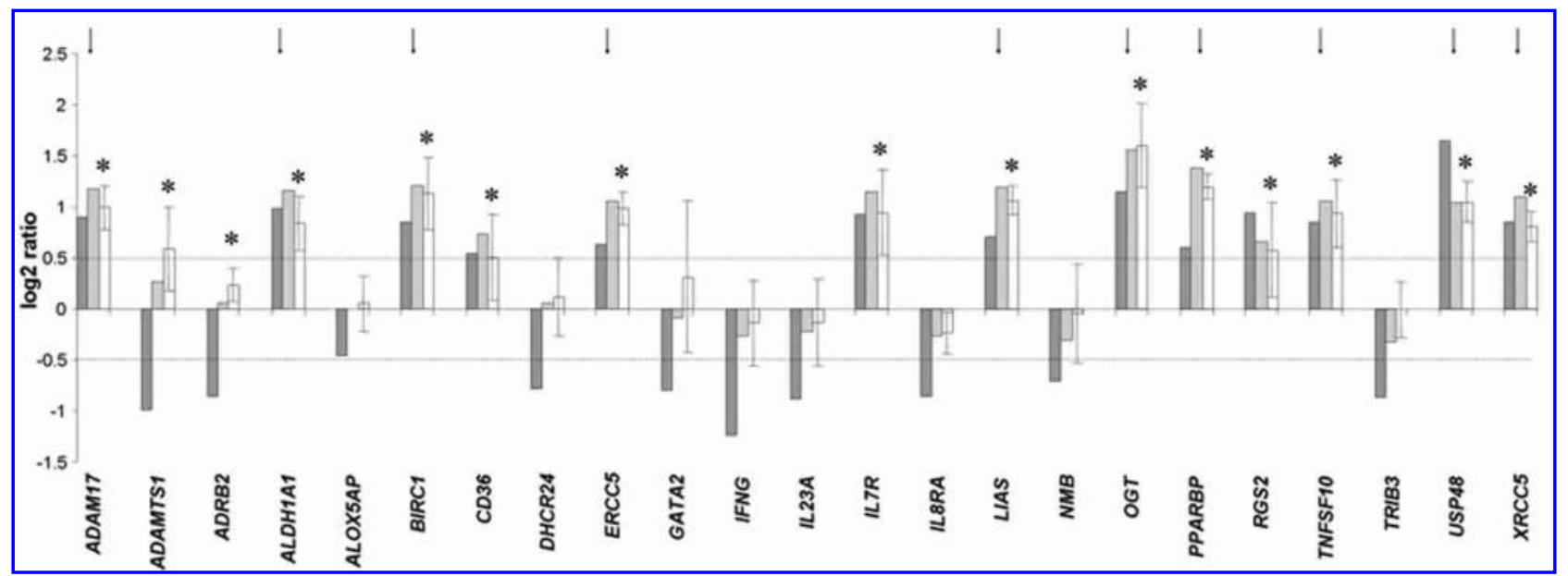

FIG. 3. Confirmation of microarray results by qPCR analysis: dark gray color bars represent the changes in gene expression detected by microarray for pooled samples. The light gray ones represent the qPCR verification of results for the microarray samples. The white bars show the mean of changes detected in individual RNA samples $(n=6$ male individuals) used in pooling for the microarray experiment and later for its qPCR verification. The changes are expressed in log2 (after/before gene expression values); error bars represent the SD and asterisks the changes at level $p<0.05$ for individual samples. Selected genes $(p<0.001)$ are denoted by arrows.

was successful with upregulated genes, but failed in all downregulated ones. Finally, based on the results from qPCR verification, and introducing stronger selection criteria for differential expression, the following 10 genes were identified as potential responders to the VOO consumption: ADAM17, ALDH1A1, BIRC1, ERCC5, LIAS, OGT, PPARBP, TNFSF10, USP48, and XRCC5. To ensure that there was no bias due to sex (the male sample was used in the microarray experiment), gene expression was additionally analyzed in the four females participating this study. The results for the 10 genes previously obtained in the male sample were confirmed in the combined sample.
We note that the 10 upregulated genes identified in response to the VOO nutritional intervention were ascertained further for their involvement in pathways associated with the development and progression of atherosclerosis.

The ingestion of $\mathrm{VOO}$ can reduce the rate of oxidation of DNA (Machowetz et al., 2007). Its phenolic content has been shown to modulate the oxidative/antioxidative status of healthy men who consumed a very low-antioxidant diet (Weinbrenner et al., 2004). Human atherosclerosis is associated with DNA damage of both circulating cells and cells of the vessel wall. DNA damage may promote atherogenesis and, in advanced lesions, induce phenotypic changes such

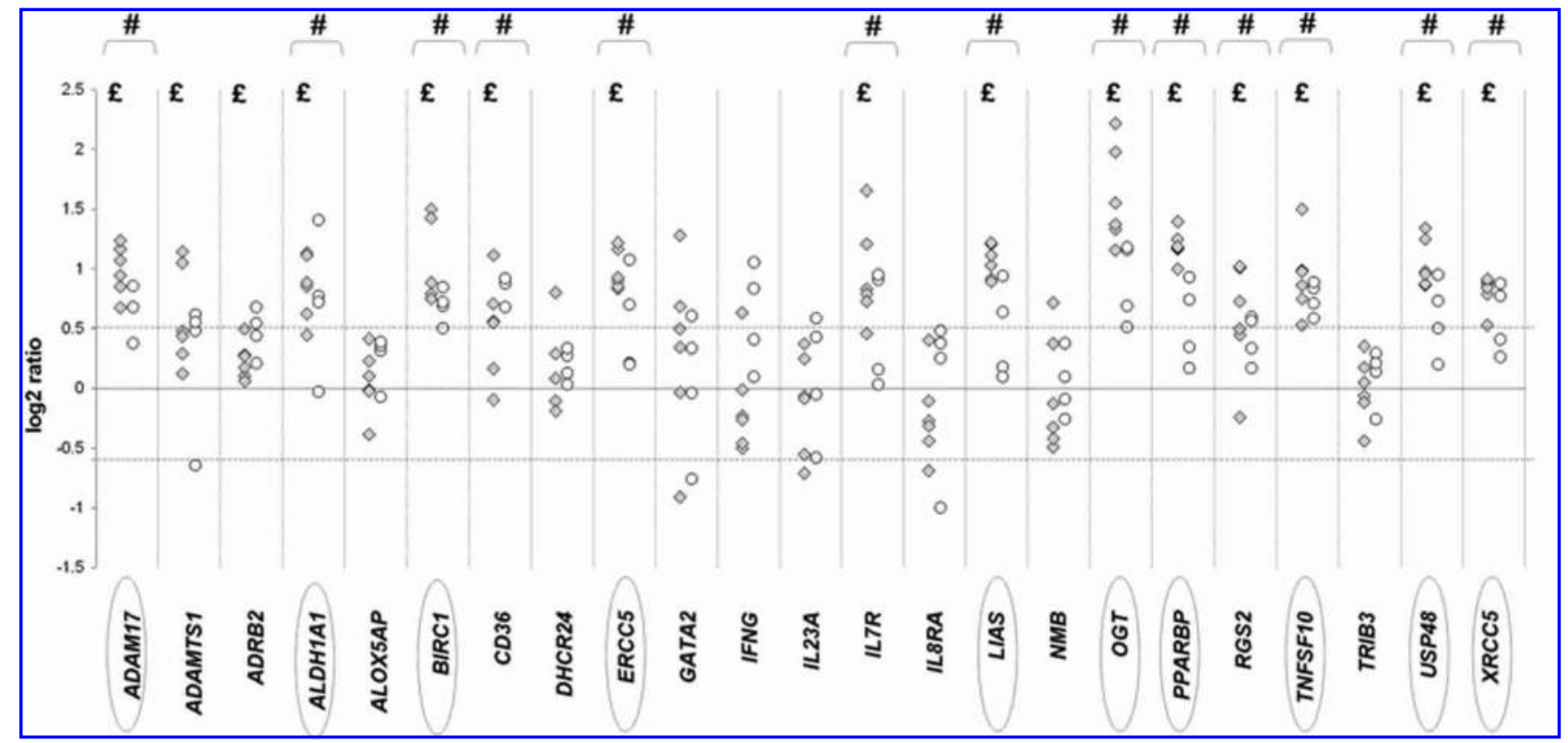

FIG. 4. Changes in gene expressions after 3 weeks of VOO consumption in individuals estimated by qPCR and expressed as $\log 2\left(\mathrm{RQ}_{\mathrm{after}} / \mathrm{RQ}\right.$ before). The changes at level $p<0.05$ were denoted as \# within the combined (males plus females) group and as $£$ within the group with male subjects. Encircled are genes which changes in expression were confirmed in both male and combined groups at level $p<0.001$. 
as cell senescence and cell death that promote unstable plaques (Mahmoudi et al., 2006). Within our set of genes responding to the 3-week VOO consumption, two belong to the DNA repairing system: ERCC5 and XRCC5. The structure-specific endonuclease ERCC5 is an indispensable core protein of the nucleotide excision repair (NER) machinery where it carries out the incision of the damage and stabilizes the protein complex on the locally unwound DNA (de Laat et al., 1999). ERCC5 suppresses UV-induced apoptosis through its endonuclease function (Clément et al., 2006) and also through the extrinsic apoptotic pathway involving caspases, but not p53 (Clément et al., 2007). The expression of this gene, as with other members of NER, could be modulated by oxidative stress (Langie et al., 2007). The XRCC5 is involved in mammalian DNA double-strand break repair process and in the mechanisms of genetic stability (Thacker and Zdzienicka, 2004). Overexpression of XRCC5 plays an important role in the repair of DNA damage induced by radiation (Chang et al., 2006).

The LIAS is currently at the early stages of investigation as very little is known about it because it was identified in humans (Stanchi et al., 2002). Nevertheless, the protein encoded by this gene is localized in mitochondria, and plays an important role in $\alpha-(+)$-lipoic acid (LA) synthesis. LA is part of a redox pair as it is the oxidized partner of the reduced form DiHydroLipoic Acid (DHLA). Both the oxidized and reduced forms of LA are antioxidants (Bast and Haenen, 2003; Moini et al., 2002). LA effectively attenuates high glucose-induced endothelial cell apoptosis, which could explain a role of LA in CVD (Meng et al., 2008). A dietary LA supplementation inhibits the atherosclerotic lesion formation in mouse models of human atherosclerosis due to its anti-inflammatory, antihypertriglyceridemic, and weight-reducing effects, and therefore, may be a useful tool in the prevention and treatment of atherosclerotic vascular diseases (Zhang et al., 2008).

Peroxisome proliferator-activated receptors (PPARs) are involved in cellular proliferation, differentiation, and apoptosis. PPAR activators have been shown to exert anti-inflammatory activities in different immunological and vascular wall cell types. PPARBP (PPAR Binding Protein) is a pivotal component of the complex that binds to nuclear receptors and a broad array of other gene-specific activators. Thus, PPARBP plays an important role in PPAR- $\gamma$ regulation (Ge et al., 2008). PPAR- $\gamma$ is predominantly expressed in intestine and adipose tissue, and is an essential transcriptional mediator of adipogenesis, lipid metabolism, insulin sensitivity, and glucose homeostasis. It is also a key player in inflammatory cells in CVDs such as hypertension, cardiac hypertrophy, congestive heart failure, and in atherosclerosis (Duan et al., 2008).

ALDH1A1 is a gene constitutively expressed in various tissues. Downregulation of ALDH1A1 has been observed in a number of chemically induced tumors, although the molecular mechanism and the implication of this decreased expression of the ALDH1A1 remain to be elucidated (Vasiliou et al., 2000). Endogenous aldehydes are formed during the metabolism of various alcohols, amino acids, biogenic amines, vitamins, steroids, and lipids or during oxidative stress. They are long-term molecules and potent electrophiles that interact with cellular constituents, including proteins and nucleic acids (Esterbauer et al., 1991). As a result, ALDHs are considered to be detoxifying enzymes. ALDH1A1 has a substrate preference for the aldehyde products of lipid peroxidation. Therefore, it is considered to protect cells from oxidative stress induced by lipid peroxidation (Choudhary et al., 2005).

Apoptosis may be inhibited by BIRC1, which restricts apoptosis by interfering with caspases. Overexpression of BIRC1 has been shown to suppress apoptosis induced by a variety of stimuli including TNF, Fas, and growth factor withdrawal (Deveraux and Reed, 1999). BIRC1, as a Nodlike receptor, is an intracellular innate immune sensor of microbes and danger signals that initiate early host responses and inflammasome formation, which are involved in the activation of inflammatory cytokines (Martinon, 2007).

Another apoptosis-related gene identified in the present study is TNFSF-10, a member of the TNF superfamily of cytokines. It plays a major role in the development and progression of atherosclerosis by inducing inflammatory processes in vascular cells and promoting the initiation, progression, and stability of atherosclerotic plaques (Kavurma and Bennett, 2008). TNFSF-10 is also an important factor in the immune response, as it has been shown to promote apoptosis of macrophages and lymphocytes. Its primary biological activity is apoptosis induction and its ability to selectively kill tumor and transformed cells, but not normal cells. Although TNFSF-10 is not constitutively expressed on the surface of the inactivated cells of the immune system, its expression is upregulated in response to stimulation with cytokines (Kayagaki et al., 1999). The number of activated $\mathrm{T}$ cells is regulated by the phenomenon of activation-induced cell death where B cells are involved (Kemp et al., 2004).

ADAM17, as a membrane-anchored metalloprotease, is required for the normal development and maturation of lymphocytes (Li et al., 2007). It controls multiple signal transduction pathways through the proteolytic release of the extracellular domain of a host of membrane-bound factors and receptors (Solomon et al., 2007). Its role is essential in the development and progression of atherosclerosis, as it is responsible for the proteolytic shedding of vascular cell adhesion molecule (VCAM), intercellular adhesion molecule (ICAM), and L-selectin (Blankenberg et al., 2003); of TNF and its receptors, which mediate cell adhesion molecules expression (Zhou et al., 2007); and of EGFR, responsible for vascular remodeling protein synthesis in vascular smooth muscle cells (Ohtsu et al., 2006). In some cases, lymphocytes could be defined as the cellular source of ADAM17 with peak expression levels at maximum clinical disease severity (Kurz et al., 2005). It has recently been shown that ADAM17 activity could be regulated by cholesterol movements in the cell membrane, altered by interaction with HDL (Tellier et al., 2008).

OGT is responsible for the posttranslational modification of cellular proteins by $\beta$-O-linked $N$-acetylglucosamine $(O-$ GlcNAc) moieties, and plays a significant role in signal transduction by modulating protein stability, protein-protein interactions, transactivation processes, and the enzyme activities of target proteins. Levels of O-GlcNAc represent a read out of nutritional availability and stress levels. The modification of proteins with $O$-GlcNAc represents a key posttranslational change that affects cellular function (Zachara and Hart, 2006). OGT is a central factor for T- and 
B-lymphocyte activation and its overexpression sensitizes T and B cells toward activation (Golks et al., 2007). OGT plays a critical role in the regulation of cell function and survival in the cardiovascular system, and may be involved in the adverse effects of metabolic disease on the heart (Fülöp et al., 2007). Decreasing OGT expression blunted this response and diminished cell survival in response to stress, while increased levels of $O$-GlcNAc protected cells against the same stress. O-GlcNAc regulates both the rate and extent of the stress-induced induction of heat shock proteins, providing a molecular basis for these findings (Zachara et al., 2004).

The USP48 was one of the genes whose expression was most significantly altered. Although data are limited concerning this gene and its role in humans, it could be of potential interest, as it is a member of the ubiquitin proteasome system (UPS). This system, principally responsible for the removal of damaged, oxidized and/or misfolded proteins (Goldberg, 2003), is involved in a number of biological processes including inflammation, proliferation and apoptosis, all of which constitute important characteristics of atherosclerosis (Herrmann et al., 2004). The ubiquitin-proteasome pathway plays a role in cellular defenses against oxLDL-induced toxicity (Vieira et al., 2000). The USP48 gene encodes a protein containing domains that associate with the family 2 of ubiquitin carboxyl-terminal hydrolases, which are involved in the processing of polyubiquitin precursors and ubiquitinated proteins via deubiquitinating (Lockhart et al., 2004). This protease was shown to be involved via NF- $\kappa$ B regulation in the regulation of vascular permeability and, thus, in control of chronic inflammatory diseases such as atherosclerosis (Kempe et al., 2005).

In conclusion, as a nutritional intervention VOO has wellestablished health benefits. By both activating the cell death pathway in certain cells and modulating the immune response, in combination with life style management, it may play a complementary antiatherogenic role. The present work suggests that VOO may be involved in several molecular pathways involved in antiatherogenic protection in humans in vivo. Defining gene expression signatures induced by this dietary agent may point toward potential targets for nutritional modulation of atherosclerosis risk in populations. It can be argued that one of the limitations of the study is the limited 3-week period of sustained VOO consumption. This design, however, permitted volunteers to be restricted to a strictly controlled low antioxidant diet, thus avoiding the interference of other antioxidants as well as other possible confounder variables, such as changes in life-style factors, which often mask the results of nutritional intervention studies. The 25-mL/day VOO dose administrated to the participants was close to that consumed in the traditional Mediterranean diet pattern (DAFNE (Data Food Networking), Dafne Reports, Dafne Publication II (July 13, 2004), http: //www.nut.uoa.gr/english/index.asp?page=202). These results collectively support future longer term prospective studies in larger cohort of subjects to discern the molecular genetic signatures underlying the beneficial effects of VOO on atherosclerosis risk.

\section{Acknowledgments}

We would like to thank the volunteers who participated in this study and Esther Menoyo, RN, for her valuable as- sistance in dealing with them. We are grateful to the Microarray Analysis group of Genomics Unit of CNIC, (Spain's National Centre for Cardiovascular Research) for their excellent technical service and to the Introgenomics team for their statistical support in microarray data processing. The CIBEROBN is initiative of the Instituto de Salud Carlos III, Madrid, Spain. The CNS Contract CP06/00100 (Montserrat Fitó) is acknowledged. This work has been supported by CICYT (SAF 2004-08173-C03-00) and partially supported by the Generalitat of Catalunya (2005 SGR 0057).

\section{Author Disclosure Statement}

No competing financial interests exist.

\section{References}

Abia, R., Pacheco, Y.M., Perona, J.S., Montero, E., Muriana, F.J., and Ruiz-Gutiérrez, V. (2001). The metabolic availability of dietary triacylglycerols from two high oleic oils during the postprandial period does not depend on the amount of oleic acid ingested by healthy men. J Nutr 131, 59-65.

Allman-farinelli, M.A., Gomes, K., Favaloro, E.J., and Petocz, P. (2005). A diet rich in high-oleic-acid sunflower oil favorably alters low-density lipoprotein cholesterol, triglycerides, and factor VII coagulant activity. J Am Diet Assoc 105, 10711079.

Badeau, M., Adlercreutz, H., Kaihovaara, P., and Tikkanen, M.J. (2005). Estrogen A-ring structure and antioxidative effect on lipoproteins. J Steroid Biochem Mol Biol 96, 271-278.

Bast, A., and Haenen, G.R. (2003). Lipoic acid: a multifunctional antioxidant. Biofactors 17, 207-213.

Blankenberg, S., Barbaux, S., and Tiret, L. (2003). Adhesion molecules and atherosclerosis. Atherosclerosis 170, 191-203.

Brunner, E.J., Mosd 1, A., Witte, D.R., Martikainen, P., Stafford, M., Shipley, M.J. et al. (2008). Dietary patterns and 15-y risks of major coronary events, diabetes, and mortality. Am J Clin Nutr 87, 1414-1421.

Chang, H.W., Kim, S.Y., Yi, S.L., Son, S.H., Song Do, Y., Moon, S.Y., et al. (2006). Expression of Ku80 correlates with sensitivities to radiation in cancer cell lines of the head and neck. Oral Oncol 42, 979-986.

Choudhary, S., Xiao, T., Vergara, L.A., Srivastava, S., Nees, D., Piatigorsky, J., et al. (2005). Role of aldehyde dehydrogenase isozymes in the defense of rat lens and human lens epithelial cells against oxidative stress. Invest Ophthalmol Vis Sci 46, 259-267.

Clément, V., Dunand-Sauthier, I., and Clarkson, S.G. (2006). Suppression of UV-induced apoptosis by the human DNA repair protein XPG. Cell Death Differ 13, 478-488.

Clément, V., Dunand-Sauthier, I., Wiznerowicz, M., and Clarkson, S.G. (2007). UV-induced apoptosis in XPG-deficient fibroblasts involves activation of CD95 and caspases but not p53. DNA Repair (Amst) 6, 602-614.

Corona, G., Deiana, M., Incani, A., Vauzour, D., Dessí, M.A., and Spencer, J.P. (2007). Inhibition of p38/CREB phosphorylation and COX-2 expression by olive oil polyphenols underlies their anti-proliferative effects. Biochem Biophys Res Commun 362, 606-611.

Covas, M.I., Nyyssönen, K., Poulsen, H.E., Kaikkonen, J., Zunft, H.J., Kiesewetter, H., et al., EUROLIVE Study Group. (2006). The effect of polyphenols in olive oil on heart disease risk factors: a randomized trial. Ann Intern Med 145, 333-341.

De Laat, W.L., Jaspers, N.G., and Hoeijmakers, J.H. (1999). Mo- 
lecular mechanism of nucleotide excision repair. Genes Dev 13, 768-785.

Deveraux, Q.L., and Reed, J.C. (1999). IAP family proteins-suppressors of apoptosis. Genes Dev 13, 239-252.

Duan, S.Z., Ivashchenko, C.Y., Usher, M.G., and Mortensen, R.M. (2008). PPAR-gamma in the cardiovascular system. PPAR Res 2008, 745804.

Duplus, E., Glorian, M., and Forest, C. (2000). Fatty acid regulation of gene transcription. J Biol Chem 275, 30749-30752.

Esterbauer, H., Schaur, R.J., and Zollner, H. (1991). Chemistry and biochemistry of 4-hydroxynonenal, malonaldehyde and related aldehydes. Free Radic Biol Med 11, 81-128.

Estruch, R., Martínez-González, M.A., Corella, D., Salas-Salvadó, J., Ruiz-Gutiérrez, V., Covas, M.I., et al., PREDIMED Study Investigators. (2006). Effects of a Mediterranean-style diet on cardiovascular risk factors: a randomized trial. Ann Intern Med 145, 1-11.

Fitó, M., Cladellas, M., De La Torre, R., Martí, J., Alcántara, M., Pujadas-Bastardes, M., et al. The members of the SOLOS Investigators. (2005). Antioxidant effect of virgin olive oil in patients with stable coronary heart disease: a randomized, crossover, controlled, clinical trial. Atherosclerosis 181, 149158.

Friedewald, W.T., Levy, R.I., and Fredrickson, D.S. (1972). Estimation of the concentration of low-density lipoprotein cholesterol in plasma, without use of the preparative ultracentrifuge. Clin Chem 18, 499-502.

Fülöp, N., Marchase, R.B., and Chatham, J.C. (2007). Role of protein O-linked $\mathrm{N}$-acetyl-glucosamine in mediating cell function and survival in the cardiovascular system. Cardiovasc Res 73, 288-297.

Ge, K., Cho, Y.W., Guo, H., Hong, T.B., Guermah, M., Ito, M., et al. (2008). Alternative mechanisms by which mediator subunit MED1/TRAP220 regulates peroxisome proliferator-activated receptor gamma-stimulated adipogenesis and target gene expression. Mol Cell Biol 28, 1081-1091.

Gimeno, E., Calero, E., Castellote, A.I., Lamuela-Raventos, R.M., De La Torre-Boronat, M.C., and Lopez-Sabater, M.C. (2000). Simultaneous determination od alpha-tocopherol and betacarotene in olive oil by RP-HPLC. J Chromatogr A 881, 255259.

Glisovic, T., Bachorik, J.L., Yong, J., and Dreyfuss, G. (2008). RNA-binding proteins and post-transcriptional gene regulation. FEBS Lett 582, 1977-1986.

Goldberg, A.L. (2003). Protein degradation and protection against misfolded or damaged proteins. Nature 426, 895-899.

Golks, A., Tran, T.T., Goetschy, J.F., and Guerini, D. (2007). Requirement for O-linked $\mathrm{N}$-acetylglucosaminyltransferase in lymphocytes activation. EMBO J 26, 4368-4379.

Hashimoto, S., Nagai, S., Sese, J., Suzuki, T., Obata, A., Sato, T., et al. (2003). Gene expression profile in human leukocytes. Blood 101, 3509-3513.

Herrmann, J., Ciechanover, A., Lerman, L.O., and Lerman, A. (2004). The ubiquitin-proteasome system in cardiovascular diseases-a hypothesis extended. Cardiovasc Res 61, 11-21.

Holvoet, P., Mertens, A., Verhamme, P., Bogaerts, K., Beyens, G., Verhaeghe, R., et al. (2001). Circulating oxidized LDL is a useful marker for identifying patients with coronary artery disease. Arterioscler Thromb Vasc Biol 21, 844-848.

Iqbal, R., Anand, S., Ounpuu, S., Islam, S., Zhang, X., Rangarajan, S., et al., INTERHEART Study Investigators. (2008). Dietary patterns and the risk of acute myocardial infarction in 52 countries: results of the INTERHEART study. Circulation 118, 1929-1937.

Kavurma, M.M., and Bennett, M.R. (2008). Expression, regula- tion and function of trail in atherosclerosis. Biochem Pharmacol 75, 1441-1450.

Kayagaki, N., Yamaguchi, N., Nakayama, M., Eto, H., Okumura, K., and Yagita, H. (1999). Type I interferons (IFNs) regulate tumor necrosis factor-related apoptosis-inducing ligand (TRAIL) expression on human T cells: a novel mechanism for the antitumor effects of type I IFNs. J Exp Med 189, 14511460.

Kemp, T.J., Moore, J.M., and Griffith, T.S. (2004). Human B cells express functional TRAIL/Apo-2 ligand after CpG-containing oligodeoxynucleotide stimulation. I Immunol 173, 892899.

Kempe, S., Kestler, H., Lasar, A., and Wirth, T. (2005). NF-kap$\mathrm{paB}$ controls the global pro-inflammatory response in endothelial cells: evidence for the regulation of a pro-atherogenic program. Nucleic Acids Res 33, 5308-5319.

Khymenets, O., Ortuño, J., Fitó, M., Covas, M.A., Farré, M., and De La Torre, R. (2005). Evaluation of RNA isolation procedures from human blood and its application for gene expression studies (Sod-1, Sod-2). Anal Biochem 347, 156-158.

Kris-Etherton, P.M., Pearson, T.A., Wan, Y., Hargrove, R.L., Moriarty, K., Fishell, V., et al. (1999). High-monounsaturated fatty acid diets lower both plasma cholesterol and triacylglycerol concentrations. Am J Clin Nutr 70, 1009-1015.

Kromhout, D. (2001). Diet and cardiovascular diseases. J Nutr Health Aging 5, 144-149.

Kurz, M., Pischel, H., Hartung, H.P., and Kieseier, B.C. (2005). Tumor necrosis factor-alpha-converting enzyme is expressed in the inflamed peripheral nervous system. I Peripher Nerv Syst 10, 311-318.

Langheinrich, A.C., and Bohle, R.M. (2005). Atherosclerosis: humoral and cellular factors of inflammation. Virchows Arch 446, 101-111.

Langie, S.A., Knaapen, A.M., Houben, J.M., Van Kempen, F.C., De Hoon, J.P., Gottschalk, R.W., et al. (2007). The role of glutathione in the regulation of nucleotide excision repair during oxidative stress. Toxicol Lett 168, 302-309.

Li, N., Boyd, K., Dempsey, P.J., and Vignali, D.A. (2007). Noncell autonomous expression of TNF-alpha-converting enzyme ADAM17 is required for normal lymphocyte development. I Immunol 178, 4214-4221.

Livak, K.J., and Schmittgen, T.D. (2001). Analysis of relative gene expression data using real-time quantitative PCR and the 2(-Delta Delta C (T)) Method. Methods 25, 402-408.

Lockhart, P.J., Hulihan, M., Lincoln, S., Hussey, J., Skipper, L., Bisceglio, G., et al. (2004). Identification of the human ubiquitin specific protease 31 (USP31) gene: structure, sequence and expression analysis. DNA Seq 15, 9-14.

Machowetz, A., Poulsen, H.E., Gruendel, S., Weimann, A., Fitó, M., Marrugat, J., et al. (2007). Effect of olive oils on biomarkers of oxidative DNA stress in Northern and Southern Europeans. FASEB J 21, 45-52.

Mahmoudi, M., Mercer, J., and Bennett, M. (2006). DNA damage and repair in atherosclerosis. Cardiovasc Res 71, 259268.

Martinon, F. (2007). Orchestration of pathogen recognition by inflammasome diversity: variations on a common theme. Eur J Immunol 137, 3003-3006.

Mauro, V.P., and Edelman, G.M. (2002). The ribosome filter hypothesis. Proc Natl Acad Sci USA 99, 12031-12036.

Meng, X., Li, Z.M., Zhou, Y.J., Cao, Y.L., and Zhang, J. (2008). Effect of the antioxidant alpha-lipoic acid on apoptosis in human umbilical vein endothelial cells induced by high glucose. Clin Exp Med 8, 43-49.

Mi, H., Guo, N., Kejariwal, A., and Thomas, P.D. (2007). PAN- 
THER version 6: protein sequence and function evolution data with expanded representation of biological pathways. Nucleic Acids Res 35, D247-D252.

Miró-Casas, E., Covas, M.I., Fitó, M., Farré-Albadalejo, M., Marrugat, J., and De La Torre, R. (2003). Tyrosol and hydroxytyrosol are absorbed from moderate and sustained doses of virgin olive oil in humans. Eur J Clin Nutr 57, 186-190.

Moini, H., Packer, L., and Saris, N.E. (2002). Antioxidant and prooxidant activities of alpha-lipoic acid and dihydrolipoic acid.Toxicol Appl Pharmacol 182, 84-90.

Morey, J.S., Ryan, J.C., and Van Dolah, F.M. (2006). Microarray validation: factors influencing correlation between oligonucleotide microarrays and real-time PCR. Biol Proced Online 8, 175-193.

Murano, K., Okuwaki, M., Hisaoka, M., and Nagata, K. (2008). Transcription regulation of rRNA gene by a multi-functional nucleolar protein, B23/nucleophosmin through its histone chaperone activity. Mol Cell Biol 28, 3114-3126.

Ohtsu, H., Dempsey, P.J., Frank, G.D., Brailoiu, E., Higuchi, S., Suzuki, H., et al. (2006). ADAM17 mediates epidermal growth factor receptor transactivation and vascular smooth muscle cell hypertrophy induced by angiotensin II. Arterioscler Thromb Vasc Biol 26, e133-e137.

Ordovas, J.M., Kaput, J., and Corella, D. (2007). Nutrition in the genomics era: cardiovascular disease risk and the Mediterranean diet. Mol Nutr Food Res 51, 1293-1299.

Palmer, C., Diehn, M., Alizadeh, A.A., and Brown, P.O. (2006). Cell-type specific gene expression profiles of leukocytes in human peripheral blood. BMC Genomics 7, 115.

Rodriguez-Rodriguez, R., Herrera, M.D., De Sotomayor, M.A., and Ruiz-Gutierrez, V. (2007). Pomace olive oil improves endothelial function in spontaneously hypertensive rats by increasing endothelial nitric oxide synthase expression. Am J Hypertens 20, 728-734.

Ross, R. (1999). Atherosclerosis is an inflammatory disease. Am Heart J 138, S419-S420.

Ruiz-Gutiérrez, V., Morgado, N., Prada, J.L., Pérez-Jiménez, F., and Suriana, F.J. (1998). Composition of human VLDL triacylglycerols after ingestion of olive oil and high oleic sunflower oil. J Nutr 128, 570-576.

Satue, M.T., Lopez, M.C., and Agramont, A. (1994). Fatty acid composition of trout oil. Food Chem 50, 363-365.

Singleton, V.L., and Ross, J.A. (1965). Colorimetry of total phenolics with phosphomolybdic-phosphotungstic acid reagent. Am J Enol Vitic 116, 144-158.

Solomon, A., Akabayov, B., Frenkel, A., Milla, M.E., and Sagi, I. (2007). Key feature of the catalytic cycle of TNF-alpha converting enzyme involves communication between distal protein sites and the enzyme catalytic core. Proc Natl Acad Sci USA 104, 4931-4936.

Srinath Reddy, K., and Katan, M.B. (2004). Diet, nutrition and the prevention of hypertension and cardiovascular diseases. Public Health Nutr 7, 167-186.

Stanchi, F., Bertocco, E., Toppo, S., Dioguardi, R., Simionati, B., Cannata, N., et al. (2001). Characterization of 16 novel human genes showing high similarity to yeast sequences. Yeast 18 , 69-80.

Swaminathan, V., Kishore, A.H., Febitha, K.K., and Kundu, T.K. (2005). Human histone chaperone nucleophosmin enhances acetylation-dependent chromatin transcription. Mol Cell Biol 25, 7534-7545.

Tellier, E., Canault, M., Poggi, M., Bonardo, B., Nicolay, A., Alessi, M.C., et al. (2008). HDLs activate ADAM17-dependent shedding. J Cell Physiol 214, 687-693.

Thacker, J., and Zdzienicka, M.Z. (2004). The XRCC genes: expanding roles in DNA double-strand break repair. DNA Repair (Amst) 3, 1081-1090.

Thomas, P.D., Campbell, M.J., Kejariwal, A., Mi, H., Karlak, B., Daverman, R., et al. (2003). PANTHER: a library of protein families and subfamilies indexed by function. Genome Res 13, 2129-2141.

Thomas, P.D., Kejariwal, A., Guo, N., Mi, H., Campbell, M.J., Muruganujan, A., et al. (2006). Applications for protein sequence-function evolution data: mRNA/protein expression analysis and coding SNP scoring tools. Nucleic Acids Res 34, W645-W650.

Trichopoulou, A., Kouris-Blazos, A., Wahlovist, M.L., Gnardellis, C., Lagiou, P., Polychronopoulos, E., et al. (1995). Diet and overall survival in elderly people. BMJ 311, 1457-1460.

Trichopoulou, A., Costacou, T., Bamia, C., and Trichopoulos, D. (2003). Adherence to a Mediterranean diet and survival in a Greek population. N Engl J Med 348, 2599-2608.

Vasiliou, V., Pappa, A., and Petersen, D.R. (2000). Role of aldehyde dehydrogenases in endogenous and xenobiotic metabolism. Chem Biol Interact 129, 1-19.

Vieira, O., Escargueil-Blanc, I., Jürgens, G., Borner, C., Almeida, L., Salvayre, R., et al. (2000). Oxidized LDLs alter the activity of the ubiquitin-proteasome pathway: potential role in oxidized LDL-induced apoptosis. FASEB J 14, 532-542.

Weinbrenner, T., Fitó, M., De La Torre, R., Saez, G.T., Rijken, P., Tormos, C., et al. (2004). Olive oils high in phenolic compounds modulate oxidative/antioxidative status in men. I Nutr 134, 2314-2321.

Zachara, N.E., and Hart, G.W. (2006). Cell signaling, the essential role of O-GlcNAc. Biochim Biophys Acta 1761, 599-617.

Zachara, N.E., O'Donnell, N., Cheung, W.D., Mercer, J.J., Marth, J.D., and Hart, G.W. (2004). Dynamic O-GlcNAc modification of nucleocytoplasmic proteins in response to stress. A survival response of mammalian cells. J Biol Chem 279, 30133-30142.

Zhang, W.J., Bird, K.E., McMillen, T.S., Leboeuf, R.C., Hagen, T.M., and Frei, B. (2008). Dietary alpha-lipoic acid supplementation inhibits atherosclerotic lesion development in apolipoprotein E-deficient and apolipoprotein E/low-density lipoprotein receptor-deficient mice. Circulation 117, 421-428.

Zhou, Z., Connell, M.C., and MacEwan, D.J. (2007). TNFR1-induced NF-kappaB, but not ERK, p38MAPK or JNK activation, mediates TNF-induced ICAM-1 and VCAM-1 expression on endothelial cells. Cell Signal 19, 1238-1248.

Address reprint requests to: Rafael de la Torre, PharmD, Ph.D. Human Pharmacology and Clinical Neurosciences Research Group IMIM-Hospital del Mar c/Dr.Aiguader 88, Barcelona 08003, Spain

E-mail: rtorre@imim.es 
This article has been cited by:

1. Vural Ozdemir , Arno G. Motulsky, Eugene Kolker , Béatrice Godard . 2009. Genome-Environment Interactions and Prospective Technology Assessment: Evolution from Pharmacogenomics to Nutrigenomics and EcogenomicsGenome-Environment Interactions and Prospective Technology Assessment: Evolution from Pharmacogenomics to Nutrigenomics and Ecogenomics. OMICS: A Journal of Integrative Biology 13:1, 1-6. [Abstract] [PDF] [PDF Plus] 